San Jose State University

SJSU ScholarWorks

Master's Theses

Master's Theses and Graduate Research

Spring 2019

\title{
Leadership Style as a Moderator of the Relationships Between Role Stressors and Organizational Commitment
}

Tanya Chellani

San Jose State University

Follow this and additional works at: https://scholarworks.sjsu.edu/etd_theses

\section{Recommended Citation}

Chellani, Tanya, "Leadership Style as a Moderator of the Relationships Between Role Stressors and Organizational Commitment" (2019). Master's Theses. 4997.

DOI: https://doi.org/10.31979/etd.ax6p-q8bm

https://scholarworks.sjsu.edu/etd_theses/4997

This Thesis is brought to you for free and open access by the Master's Theses and Graduate Research at SJSU ScholarWorks. It has been accepted for inclusion in Master's Theses by an authorized administrator of SJSU ScholarWorks. For more information, please contact scholarworks@sjsu.edu. 


\title{
LEADERSHIP STYLE AS A MODERATOR OF THE RELATIONSHIPS BETWEEN ROLE STRESSORS AND ORGANIZATIONAL COMMITMENT
}

\author{
A Thesis \\ Presented to \\ The Faculty of the Department of Psychology \\ San José State University \\ In Partial Fulfillment \\ of the Requirements for the Degree \\ Masters of Science
}

by

Tanya Chellani

May 2019 
(C) 2019

Tanya Chellani

ALL RIGHTS RESERVED 
The Designated Thesis Committee Approves the Thesis Titled

LEADERSHIP STYLE AS A MODERATOR OF THE RELATIONSHIPS BETWEEN ROLE STRESSORS AND ORGANIZATIONAL COMMITMENT

by

Tanya Chellani

APPROVED FOR THE DEPARTMENT OF PSYCHOLOGY

SAN JOSÉ STATE UNIVERSITY

May 2019

Dr. Howard Tokunaga Department of Psychology

Dr. Megumi Hosoda Department of Psychology

Michelle Deneau, M.S. Adobe Inc. 


\title{
ABSTRACT \\ LEADERSHIP STYLE AS A MODERATOR OF THE RELATIONSHIPS BETWEEN ROLE STRESSORS AND ORGANIZATIONAL COMMITMENT
}

\author{
by Tanya Chellani
}

The purpose of the present study was to examine the moderating effect of leadership style on the relationships between role stressors and organizational commitment. The study hypothesized that negative relationships between role conflict and role ambiguity and both affective and normative commitment would be weaker for employees who perceived their supervisors as relationship-oriented rather than task-oriented.

Furthermore, the study explored the direct relationship between role stressors and continuance commitment, along with the moderating effect of leadership style on this relationship. Responses to an online survey from 126 employees were analyzed using hierarchical multiple regression. Results showed that leadership style did not moderate the relationships between role conflict and role ambiguity and all three types of organizational commitment. Results also indicated that there were nonsignificant relationships between role conflict and role ambiguity and continuance commitment. Results implied that role stress impacts organizational commitment to the same extent for employees who have task-oriented leaders and those who have relationship-oriented leaders. Based on these findings, there is a need for research examining additional leadership styles that may serve as moderators of role stress-organizational commitment relationships. 


\section{ACKNOWLEDGEMENTS}

I would like to thank my thesis committee for their numerous hours spent revising my thesis. Howard Tokunaga, thank you for being my thesis chair and guiding me throughout the past year. Megumi Hosoda, thank you for your insightful comments and valuable input. Michelle Deneau, thank you for your contribution to my academic and professional development. To my family and friends, thank you for continuously supporting me in my academic endeavors. Akshay Soma, thank you for your endless patience and encouragement throughout my master's program. 


\section{TABLE OF CONTENTS}

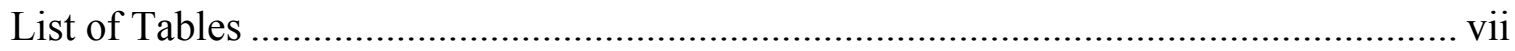

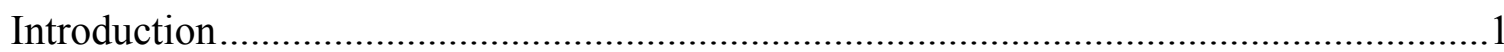

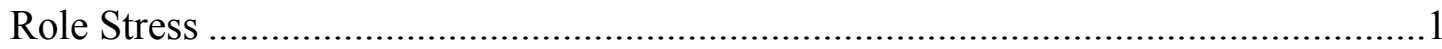

Organizational Commitment ....................................................................................

Direct Relationships Between Role Conflict and Role Ambiguity and

Organizational Commitment............................................................................6

Moderated Relationships Between Role Conflict and Role Ambiguity and

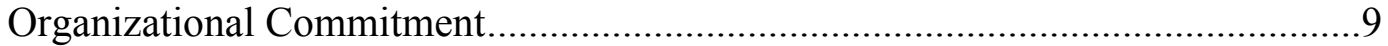

Leadership Style.........................................................................................13

Goal of the Present Study ....................................................................................16

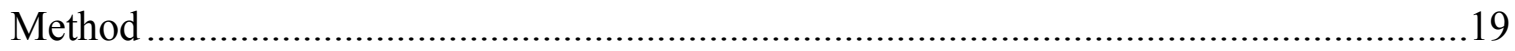

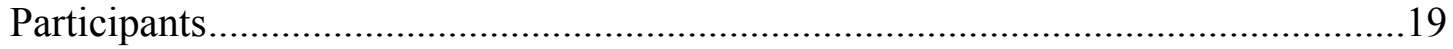

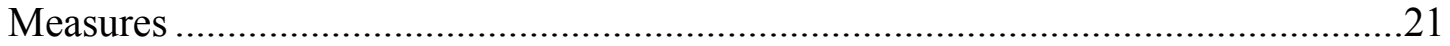

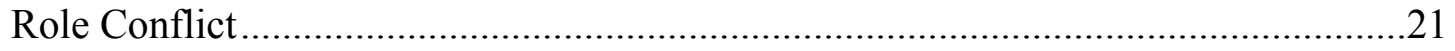

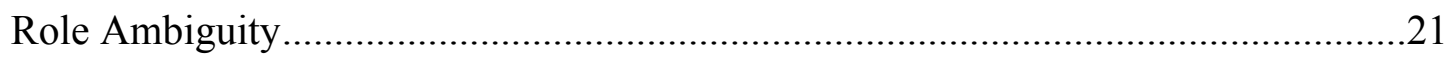

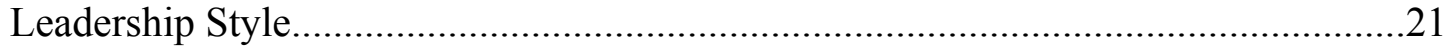

Organizational Commitment ........................................................................22

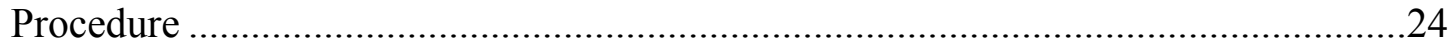

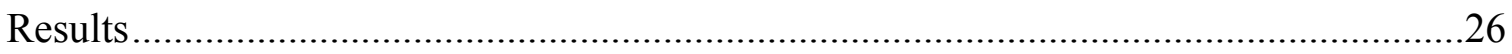

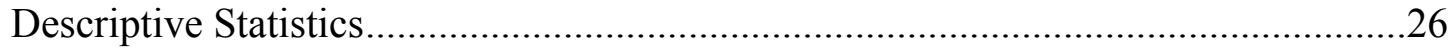

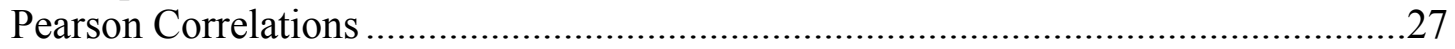

Test of Hypotheses and Research Question............................................................28

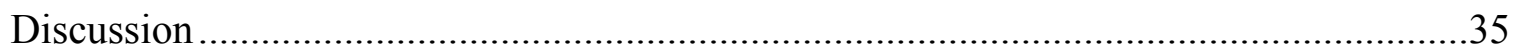

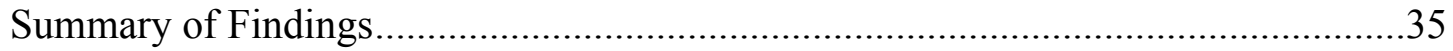

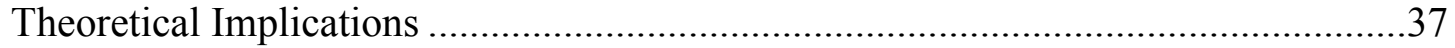

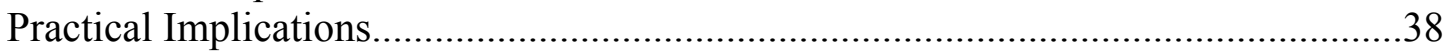

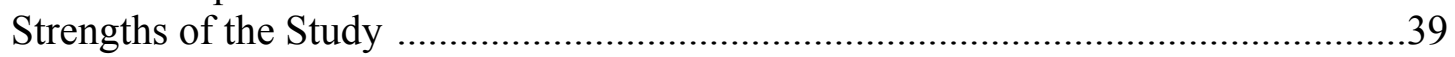

Limitations of the Study and Directions for Future Research ......................................39

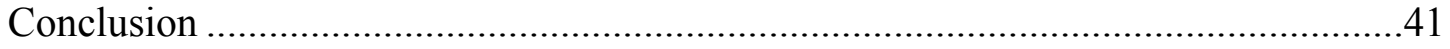

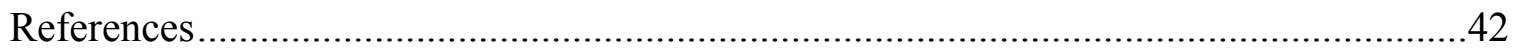

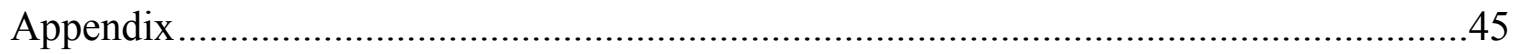

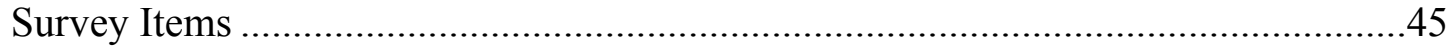




\section{LIST OF TABLES}

Table 1. Demographic Characteristics of Participants

Table 2. Means, Standard Deviations, and Bivariate Correlations among Variables .......26

Table 3. Hierarchical MRC for the Moderating Effect of Leadership Style (Affective Commitment)

Table 4. Hierarchical MRC for the Moderating Effect of Leadership Style (Normative Commitment)

Table 5. Hierarchical MRC for the Moderating Effect of Leadership Style (Continuance Commitment) 


\section{Introduction}

Role conflict and role ambiguity, two of the most commonly cited sources of role stress, have been linked to a variety of unfavorable behavioral and attitudinal outcomes (Agarwal \& Ramaswami, 1993; King \& Sethi, 1997; Lopopolo, 2002;

Malik \& Malik, 2010; Yousef, 2002; Zakari, 2011). However, research that examines potential moderators of these relationships is scarce. Given that committed employees are an asset to organizations (Mathieu \& Zajac, 1990), there is a need for research that examines variables that can potentially mitigate the negative impact of role stress on commitment to one's organization. Thus, the primarily goal of this study was to determine whether leadership style impacts the strength of the relationships between role conflict and role ambiguity and three types of organizational commitment.

\section{Role Stress}

Within the broader psychological phenomenon of stress, job stress is the manifestation of harmful physical and emotional outcomes that result when the requirements of one's job do not align with one's competencies, resources, or needs (Netemeyer, Maxham, \& Pullig, 2005). Some consequences of job stress include illnesses, exhaustion, and depression, which arise when challenges on the job are transformed into demands that are beyond one's coping ability and thus cannot be met. According to results of the Stress in America survey, $58 \%$ of Americans indicate that work is a significant source of stress (American Psychological Association, 2017). Resulting from the interactions between workers and their working conditions, job stress leads to poor health and counterproductive behaviors, 
which in turn affect the entire functioning of organizations. It is estimated that job stress costs employers about $\$ 300$ billion each year due to lost productivity, absenteeism, turnover, and medical, legal, and insurance costs, which demonstrates the detrimental impact of job stress on the bottom line (American Institute of Stress, 2014).

Various organizational variables have been found to cause workplace stress. Cooper and Marshall (1976) pointed out five sources of stress at work: intrinsic to the job, career development, relationships at work, organizational structure and climate, and role in the organization. Of these five sources, stress related to one's role is a plausible consequence of the added pressure organizations place upon their employees in order to stay competitive in today's fast-growing market. As organizations place greater responsibilities upon their employees, the employees' workloads increase. This augments the extent to which employees are expected to contribute to their organizations' progress, therefore changing their job role and possibly causing their stress levels to increase.

Role stress, as a construct distinct from the larger concept of job stress, is defined as stress workers experience because of their role in their organizations (Netemeyer et al., 2005). Kahn, Wolfe, Quinn, Snoek, and Rosenthal (1964) found that role conflict and role ambiguity are key sources of role stress. Although these two stressors share certain consequences, how each take shape has been shown to be generally independent (Yousef, 2002). Role conflict is the incompatibility in communicated expectations that influence perceived role performance (Rizzo, House, \& Lirtzman, 1970). Role conflict occurs when an individual confronts conflicting job roles, each with expectations that are difficult to meet simultaneously. Those who experience role conflict are thus unable to successfully 
meet all of the requirements of their roles. An individual trying to meet the demands of two or more groups at work, such as customers and stakeholders, may fail to do so. For example, when a change in customer relationship management leads stakeholders to prioritize a new sales culture, it may be troublesome for employees to satisfy both internal demands to sell as well as external demands for quality service. With more employees today concurrently occupying several roles, role conflict is likely to arise.

Role ambiguity, on the other hand, refers to a lack of adequate information in regard to the responsibilities and expectations of one's role (Rizzo et al., 1970). For example, poorly designed job descriptions coupled with a lack of managerial guidance might result in employees not having full clarity on which work behaviors are appropriate and which are not. A perceived need for more clarity and structure induces role-related stress, resulting in employees performing at lower levels than they would if they had a clear understanding of job requirements. Unlike role conflict, which involves incongruent roles, role ambiguity can be experienced within a single role. However, both role conflict and role ambiguity are similar in that they have objective and subjective forms. Objective forms are due to conditions in the work environment, whereas subjective forms are due to the state of the person (Kahn et al., 1964). Objective factors include organizational structure and policies, while subjective factors include personal motives and values. The interplay between these factors affects the response employees have toward their roles.

Existing research has demonstrated the profound impact role conflict and ambiguity have on individuals within organizations. Various studies have linked role conflict and role ambiguity to behavioral and attitudinal outcomes. A meta-analysis by Örtqvist and 
Wincent (2006) on the prominent outcomes of job stress revealed that role conflict was related to greater levels of emotional exhaustion, tension, and propensity to quit, as well as lower levels of job satisfaction, performance, and organizational commitment.

Additionally, these researchers found that role ambiguity was related to greater levels of emotional exhaustion, tension, propensity to quit, and depersonalization, as well as lower levels of job satisfaction, performance, organizational commitment, and personal accomplishment.

As conveyed by existing literature, individual outcomes are more favorable when role stress is low. With the harmful effects of role stress being so widespread, organizational leaders should prioritize taking active steps to mitigate these stressors by understanding and helping to reduce problems encountered in role performance. They should aim to provide employees with nonconflicting role expectations and provide a clear explanation of specific behaviors that are needed to accomplish their jobs. Most importantly, these actions would likely be helpful in maintaining employees' levels of commitment to their organizations. The next section discusses the importance of organizational commitment within an organization.

\section{Organizational Commitment}

Organizational commitment has been one of the most widely studied constructs in the realm of work-related research, and several definitions have been constructed.

O'Reilly (1986) described organizational commitment as an individual's psychological bond to the organization, including a sense of job involvement, loyalty and belief in the values of the organization" (p. 492). Adding to this definition, Meyer and Allen (1991) 
proposed a three-dimensional psychological construct of organizational commitment comprised of affective, normative, and continuance commitment. This model recognizes that employees can experience varying degrees of each form of organizational commitment (Meyer, Allen, \& Smith, 1993).

The three dimensions of organizational commitment illustrate the different ways it can develop. Affective commitment refers to one's intrinsic emotional attachment to and sense of belonging in an organization (Meyer \& Allen, 1991). This personal desire to stay in one's organization comes from having positive workplace experiences marked by congruence between personal and organizational values and goals (Beck \& Wilson, 2000). Normative commitment is one's perceived righteousness of remaining in an organization (Meyer \& Allen, 1991). Employees with this type of commitment tend to feel a moral duty, which has likely accumulated and increased their attachment over the years. Employees can feel this sense of obligation if their organization has invested resources in them to support their growth. Lastly, continuance commitment refers to feeling an economic need to stay at one's organization (Meyer \& Allen, 1991). This commitment is based on a recognition of the associated costs of leaving, such as lack of alternative employment or the loss of health or social benefits.

All three dimensions of commitment are associated with different types of employee motivation. Unlike individuals with affective commitment, employees with continuance commitment may be inclined to only meet the minimum standards that are expected of them. Furthermore, affective commitment is marked by a strong promotion focus in pursuit of goals (Luchak \& Gellatly, 2007), in which goals are represented as aspirations 
and accomplishments. However, normative and continuance commitment are characterized by a prevention focus, in which individuals view complying with social pressures or maintaining personal responsibilities as their goals.

Understanding the relationships between role conflict and role ambiguity and organizational commitment, including variables that may moderate these relationships, is important given that organizational commitment is related to various outcomes. According to a meta-analysis by Mathieu and Zajac (1990), consequences of organizational commitment include a decrease in intention to search for job alternatives and leave one's job, and an increase in attendance. Therefore, organizations should strive to boost employee commitment in order to help maximize the occurrence of these positive outcomes. The next section provides a summary of literature that has studied the direct relationships between role stressors and organizational commitment.

\section{Direct Relationships Between Role Conflict and Role Ambiguity and Organizational Commitment}

Various studies have found significant direct relationships between role conflict and organizational commitment. Overall, most of the findings of the existing literature on this topic are consistent with the Role Episode Model (Kahn et al., 1964), which shows the interactions between role senders and the role incumbent. This model purports that persistent role stressors are likely to deplete resources and have a dysfunctional effect on attitudinal and behavioral job outcomes, including organizational commitment. More specifically, the negative linkages between role conflict and role ambiguity and organizational commitment are in line with Social Exchange Theory (Cropanzano \& Mitchell, 2005), which points out that social change is a process of interactions between 
individuals. This theory proposes that those who experience high role stress will view their organizations in a negative light, causing them to diminish their identification and attachment with them.

A study by Zakari (2011) looked at the effect of role stressors on nursing faculty in an academic setting and found that role conflict was negatively correlated with affective commitment. Similarly, Lopopolo (2002) and Malik and Malik (2010) found that role conflict negatively influenced affective commitment among managers. Both of these studies demonstrated that employees who faced role stress in the form of conflicting roles were less likely to have an emotional attachment to their organizations. Zakari (2011) also found that employees who faced conflicting roles felt less obligated to stay at their organizations. Zakari (2011) found a negative association between role conflict and continuance commitment, which conveyed that employees who faced conflicting roles had lower levels of commitment based on the perceived costs of leaving. Contrary to this, King and Sethi (1997) reported that role conflict was positively correlated with continuance commitment.

Significant direct relationships between role ambiguity and organizational commitment have also been demonstrated. A study by Yousef (2002) investigated the impact of role stressors on organizational commitment among employees across 30 organizations. Results showed that role ambiguity was negatively related to affective commitment. This finding was consistent with Agarwal and Ramaswami's (1993) finding on the relationships between various task, role, supervisory-behavior, and organizational structure-related factors (e.g., task variety, role conflict, initiation of structure, and 
participation) and salesperson affective commitment, among which role ambiguity was found to be the strongest predictor of affective commitment. Both of these studies showed that employees who dealt with unclear role expectations had less of an emotional desire to stay at their organizations. The studies by Zakari (2011) and Yousef (2012) also portrayed a negative relationship between role ambiguity and normative commitment, suggesting that when vague roles were placed upon employees, they felt less morally obliged to stay at their organizations. Zakari (2011) found a negative relationship between role ambiguity and continuance commitment, such that in the presence of ambiguous roles, employees were less committed based on the perceived costs of leaving. However, both Yousef (2002) and King and Sethi (1997) found that role ambiguity was positively correlated with continuance commitment.

The existing research pertaining to the relationships between role stressors and organizational commitment reveals that increasing levels of role conflict or role ambiguity lead to less commitment to one's organization based on wanting to stay (affective commitment) or feeling an obligation to stay (normative commitment). In particular, role conflict reduces affective commitment because it interferes with personal willingness to exert effort on behalf of the organization, while role ambiguity reduces affective commitment because it weakens the link between the employee's role and the accomplishment of organizational goals (Salancik, 1977).

There are mixed findings pertaining to the impact these role stressors have on how committed employees are because they need to stay (continuance commitment). This may be due to additional variables that alter the nature of the relationships between role 
conflict and role ambiguity and continuance commitment. The next section provides a summary of literature that has examined moderators in the relationships between these role stressors and organizational commitment.

\section{Moderated Relationships Between Role Conflict and Role Ambiguity and Organizational Commitment}

Although the direct relationships between role stressors and organizational commitment have been studied extensively, only a few researchers have sought to demonstrate the presence of variables that moderate these relationships. Ackfeldt and Malhotra (2013) stipulated that professional development and empowerment were two organizational variables that could reduce the effect of role stressors on affective and continuance commitment, as they have shown to be powerful management tools that help in understanding employee attitudes. Professional development refers to professional growth that can occur when employees are given opportunities that align with their interests and goals (Hart, 1994). Empowerment refers to situations in which a manager gives employees the autonomy to make daily job-related decisions (Hartline \& Ferrell, 1996).

Ackfeldt and Malhotra (2013) hypothesized that professional development would moderate the relationships between role conflict and role ambiguity and affective commitment, such that when professional development is low, there are negative relationships between role conflict and role ambiguity and affective commitment, but when professional development is high, these relationships are weaker. The authors believed that professional development would reduce the negative impact of role conflict and role ambiguity on affective commitment since professional development 
may allow employees to have up-to-date competencies needed to meet the challenges of increasing role stress. Results showed that professional development did not in fact moderate the relationship between role ambiguity and affective commitment. On the other hand, professional development did moderate the relationship between role conflict and affective commitment, but not in the manner that was hypothesized. When professional development was low, the relationship between role conflict and affective commitment was negative; however, when professional development was high, the relationship between role conflict and affective commitment was positive.

Ackfeldt and Malhotra (2013) also hypothesized that professional development would moderate the relationships between role conflict and role ambiguity and continuance commitment, such that when professional development is low, the relationships between role conflict and role ambiguity and continuance commitment are positive, but when professional development is high, these relationships are weaker. This was justified by their belief that a greater sense of accomplishment is likely to decrease feelings of helplessness and thus help decrease the feeling of a need to stay. Results showed that professional development did not moderate the relationship between role ambiguity and continuance commitment, but did moderate the relationship between role conflict and continuance commitment. When professional development was low, the relationship between role conflict and continuance commitment was in fact positive. However, unlike what was expected, when professional development was high, this positive relationship became stronger. This finding may be explained by the notion 
that employees with continuance commitment might view professional development as a burden that is necessary in order to remain at the organization.

In addition to professional development, Ackfeldt and Malhotra (2013) also hypothesized that empowerment would moderate the relationships between role ambiguity and role conflict and affective commitment, such that when empowerment is low, the relationships between role conflict and role ambiguity and affective commitment are negative, but when empowerment is high, these relationships are weaker. The researchers believed that when empowerment was high, employees would continue to have a psychological attachment to the organization even in the event of role conflict and role ambiguity due to their ability to take control of the situation. Results showed that empowerment did not moderate the relationship between role conflict and affective commitment, but did moderate the relationship between role ambiguity and affective commitment. When empowerment was low, the relationship between role ambiguity and affective commitment was in fact negative. However, contrary to what the authors stipulated, when empowerment was high, this negative relationship became stronger. This finding may be due to the fact that role ambiguity does not enable employees to use the authority given to them in a way that helps them meet goals.

It was also hypothesized that empowerment would moderate the relationships between role ambiguity and role conflict and continuance commitment, such that when empowerment is low, the relationships between role conflict and role ambiguity and continuance commitment are positive, and when empowerment is high, these relationships 
are weaker. This was justified by their belief that that high empowerment would help reduce feelings of helplessness and therefore decrease the feeling of a need to stay. However, this hypothesis was not supported, as empowerment did not moderate either of the two relationships.

Overall, this study made a valuable contribution to existing literature by highlighting that the effects of moderators are likely to be different among the different dimensions of commitment. The study demonstrated that the negative relationship between role ambiguity and affective commitment was stronger when empowerment was high but that empowerment did not influence the relationships between both role stressors and continuance commitment. As a moderator, professional development was more impactful—the negative relationship between role conflict and affective commitment was reversed when professional development was high, while the positive relationship between role conflict and continuance commitment was stronger when professional development was high. According to results of this study, professional development is more beneficial in increasing affective commitment than empowerment.

For companies that care about increasing the value their employees bring to the bottom line, examining situations that can alleviate the negative effects of role stress can be valuable. In their summary of research on workplace stress, Kahn and Byosiere (1992) pointed out that "organizational theory and research have been too little concerned with organizational and interpersonal factors that might serve as moderators, buffers, or even as antidotes to stresses and their effects" (p. 572). As organizations have more direct control 
over the strategic use of organizational variables, as opposed to individual or situational variables, there is a need for further research examining organizational variables as moderators of the relationships between role stressors and organizational commitment. One such organizational variable, leadership style, has been commonly associated with worker attitudes, including organizational commitment (Jackson, Meyer, \& Wang, 2013). The next section discusses how leadership style has been shown to moderate relationships between role stressors and important individual-level outcomes.

\section{Leadership Style}

Leadership style is a qualitative variable that involves different types of approaches leaders take to provide direction, implement plans, and motivate employees (Newstrom \& Davis, 1993). Various leadership styles have been presented, some of which overlap, including transformational leadership (Bass, 1985), laissez-faire leadership (Lewin, Lippitt, \& White, 1939), charismatic leadership (Conger \& Kanungo, 1987), servant leadership (Greenleaf, 1977), task-oriented leadership (Stodgill, 1974), and relationshiporiented leadership (Stodgill, 1974).

Leadership style is determined by relatively constant explicit and implicit behavioral patterns in leaders, such as establishing control over employees, prioritizing employees' needs, or inspiring employees through intellectual stimulation. As a leader's style tends to remain stable over time, leadership style can affect the magnitude of employees' attitudinal manifestations of stress. For example, authoritarian leaders, who tend to dictate employees without enabling them to participate in decision-making, can induce stress among employees due to a lack of agreement with work procedures. Therefore, the 
present study proposes that leadership style is a plausible moderator of the relationships between role stressors and organizational commitment.

Among the various leadership models that have been created, two leadership styles that are believed to encompass numerous leadership behaviors are the task-oriented and relationship-oriented styles (Forsyth, 2010). Thus, the moderating effects of these two leadership styles as they relate to role-related stress and organizational commitment would be worth studying. These two leadership styles originated from studies conducted at the Ohio State University based on the findings of Stodgill's (1948) research. These studies narrowed leader behavior into two dimensions: task-oriented (initiating structure) and relationship-oriented (consideration).

Task-oriented leadership is a behavioral approach in which the leader focuses on tasks needed to be performed in order to reach organizational goals. Task-oriented leaders ensure that employees have a clear understanding of their roles and that duties are completed on time. Moreover, they inform subordinates of work procedures and develop criteria for monitoring progress and measuring successful performance. Task-oriented leaders are driven to maintain high performance standards due to their achievementoriented nature (Stodgill, 1948).

In contrast, relationship-oriented leadership is a behavioral approach in which the leader focuses on the satisfaction and motivation of team members. Leaders with this style prioritize supporting their employees, fostering a friendly work environment, and building relationships through frequent communication. Leaders who adopt this style lead in a personable manner, as they are concerned with the well-being of their employees. 
Relationship-oriented leaders are motivated by their belief that establishing a positive work culture takes precedence over meeting goals (Stodgill, 1948).

Leadership style has been established as a moderator of the relationships between role stressors and another individual-level outcome, namely health. For example, Abassi (2018) studied the moderating effects of transformational and laissez-faire leadership styles on the relationships between role conflict and role ambiguity and general health outcomes in a sample of medical doctors. Transformational leaders take steps in influencing the attitudes and behaviors of their followers; their primary motive is to spur change in their followers and the organization. These types of leaders have a strong vision and seek to stimulate growth while meeting the needs of employees (Daft, 2008). On the other hand, leaders who adopt a laissez-faire style have a hands-off approach and make few decisions for their followers, as they trust that their subordinates can manage their work independently (Lewin et al., 1939).

Based on the idea that transformational leaders would be viewed as supportive, Abassi (2018) proposed that transformational leadership would reduce the negative impact of role conflict and role ambiguity on employees' health conditions. As expected, results showed that when leaders took active steps to inspire and motivate their employees, the negative relationships between the role stressors and health were weaker than when leaders did not take this approach. It was also hypothesized that laissez-faire leadership would increase the negative impact of role stressors on health due to employees' needs being unmet by such leaders. Results showed that when leaders avoided responsibility, the negative relationships between role stressors and health were stronger than when leaders did not 
avoid responsibility. As this study demonstrates how leadership style can alter the manner in which role stressors affected health, it highlights the value of further research examining the influence of leadership behaviors. While this study shows that transformational leaders are more successful in reducing the negative impact of role stressors on health, it is likely that transformational leaders demonstrate both task-oriented and relationship-oriented behaviors. Prior research has not measured the impact of taskand relationship-oriented leadership styles in a leadership moderation study involving role stressors and commitment, which is the goal of the present study.

\section{Goal of the Present Study}

As research examining potential moderators of role stress-organizational commitment relationships is scarce, the goal of the present study is to understand whether leadership style, as measured by task- and relationship-oriented behaviors, moderates the relationships between role conflict and role ambiguity and organizational commitment. This study builds upon previous research since the relationships between each type of role stress and commitment will be measured and described separately. The reasoning behind this stems from the possibility that role conflict and role ambiguity differ in terms of how they affect the three types of commitment, and that task- and relationship-oriented leadership styles may affect each relationship differently. Thus, the influence of leadership style on the relationships between role stressors and commitment could be better understood when the dimensions of each are studied separately.

According to the Situational Leadership Theory (Hersey \& Blanchard, 1969), there is no single "best" style of leadership. This theory proposes that leaders should engage in 
behaviors that are appropriate for the situation and their subordinates. Thus, the present study proposes that when subordinates face role conflict and role ambiguity, leaders should demonstrate higher levels of relationship-oriented leadership than task-oriented leadership. An effort to build supportive relationships may help to instill a sense of comfort in employees, which would help minimize the negative effects of role stressors on subordinates' organizational commitment. In the presence of role-related stress, employees who perceive their leaders as more relationship-oriented would be more inclined to stay with their company, due to having a stronger support system. Therefore, the following hypotheses were tested:

Hypothesis 1: Leadership style will moderate the relationships between role conflict and role ambiguity and affective commitment, such that the negative relationships between role conflict and role ambiguity and affective commitment will be weaker for employees who perceive their leaders as being relationship-oriented than for those who perceive their leaders as being task-oriented.

Hypothesis 2: Leadership style will moderate the relationships between role conflict and role ambiguity and normative commitment, such that the negative relationships between role conflict and role ambiguity and normative commitment will be weaker for employees who perceive their leaders as being relationship-oriented than for those who perceive their leaders as being task-oriented.

As there have been mixed findings in regard to the effect of role stressors on continuance commitment, this study sought to answer the following research question: 
Research question: What are the direct relationships between role conflict and role ambiguity and continuance commitment, and are they moderated by leadership style? 


\section{Method}

\section{Participants}

Participants were part of the researcher's personal and professional network and were recruited via social media. A total of 200 individuals initially participated in the study. However, 53 participants were excluded from analyses because they were either selfemployed or unemployed, or had missing data. Furthermore, 21 participants reported that their supervisors displayed an identical amount of relationship-orientated leadership and task-oriented leadership; since one leadership style could not be computed for these participants, they were excluded from analyses as well. Thus, the final sample consisted of 126 individuals. The demographic characteristics of these participants are reported in Table 1. The sample consisted of 48 males (38.1\%) and 78 females (61.9\%). In terms of age, $79.3 \%$ of the participants were below the age of 35 , with $46.8 \%$ under 25 and $32.5 \%$ between the ages of 25 and 34. In terms of the average number of hours worked per week, $65.1 \%$ worked at least 40 hours per week (50.8\% working $40-49$ hours and $14.3 \%$ working 50 or more hours). 
Table 1

Demographic Characteristics of Participants $(N=126)$

\begin{tabular}{lrr}
\hline \multicolumn{1}{c}{ Variable } & $n$ & $\%$ \\
\hline $\begin{array}{l}\text { Gender } \\
\text { Male }\end{array}$ & 48 & 38.1 \\
Female & 78 & 61.9 \\
& & \\
Age $\quad$ Under 25 & 59 & 46.8 \\
25-34 years & 41 & 32.5 \\
35-44 years & 7 & 5.6 \\
$45-54$ years & 13 & 10.3 \\
55-64 years & 5 & 4.0 \\
65 or older & 1 & .8 \\
& & \\
Average Number of Hours Worked per Week & & \\
Less than 20 & 9 & 7.1 \\
$20-29$ & 15 & 11.9 \\
$30-39$ & 20 & 15.9 \\
$40-49$ & 64 & 50.8 \\
50 or more & 18 & 14.3 \\
\hline
\end{tabular}




\section{Measures}

The variables listed below were measured using a five-point Likert scale ranging from Strongly Disagree (1) to Strongly Agree (5).

Role conflict. Role conflict is the incompatibility in communicated expectations that influence perceived role performance (Rizzo, et al., 1970). Role conflict was measured using items adapted from Rizzo et al.'s (1970) Role Conflict and Ambiguity (RCA) Scale. The role conflict subscale consisted of three items: "I have to oppose rules or policies in order to carry out my work assignments," "I do things in my work that are accepted by one person but not accepted by others," and "I receive conflicting work requests from two or more people." Scores on the three items were averaged to yield a single score indicating role conflict. The scale demonstrated low internal consistency $(\alpha=$ $.54)$.

Role ambiguity. Role ambiguity is a lack of adequate information in regard to the responsibilities and expectations of one's role (Rizzo et al., 1970). Role ambiguity was measured using items adapted from Rizzo et al.'s (1970) Role Conflict and Ambiguity (RCA) Scale. The role ambiguity subscale consisted of three items: "My job has

clearly defined goals and objectives," "I feel certain about how much authority I have in my job," and "I know what the responsibilities are in my job role." All of the items in this subscale were reverse-coded to reflect ambiguity. Scores on the three items were averaged to yield a single score indicating role ambiguity. The scale demonstrated moderate internal consistency $(\alpha=.68)$.

Leadership style. Leadership style was measured using Northhouse's (2009) Style 
Questionnaire. The task-orientation and relationship-orientation subscales each consisted of six items.

Task-oriented leadership is a behavioral approach in which the leader focuses on the tasks that need to be performed in order to reach organizational goals (Stodgill, 1948). Example items in the task-orientation subscale were "My supervisor makes suggestions about how to solve problems," "My supervisor sets standards of performance for group members," and "My supervisor defines role responsibilities for each group member." The scale demonstrated high internal consistency $(\alpha=.82)$.

Relationship-oriented leadership is a behavioral approach in which the leader focuses on the satisfaction and motivation of team members (Stodgill, 1948). Example items in the relationship-orientation subscale included "My supervisor is friendly with members of the group," "My supervisor helps group members feel comfortable," and "My supervisor shows concern for the well-being of group members. " The scale demonstrated high internal consistency $(\alpha=.82)$.

For both subscales, the six items were averaged to obtain single scores for relationship-orientated leadership and task-oriented leadership, which were then compared to each other. Participants with a greater relationship task-oriented leadership score perceived their supervisor as being relationship-oriented, while participants with a greater task-oriented leadership score perceived their supervisor as being task-oriented. Each person was thus placed into one of two categories: relationship-oriented leadership or task-oriented leadership.

Organizational commitment. Organizational commitment refers to "an individual's 
psychological bond to the organization, including a sense of job involvement, loyalty and belief in the values of the organization" (O'Reilly, 1986, p. 492). Organizational commitment was measured using items adapted from the Meyer and Allen's (1996) Organizational Commitment Scale. The affective, normative, and continuance commitment subscales each consisted of four items. For each subscale, all of the scores were averaged to obtain single scores for affective, normative, and continuance commitment.

Affective commitment is one's intrinsic emotional attachment to and sense of belonging in the organization (Meyer \& Allen, 1991). The items in the affective commitment subscale were "I would be happy to spend the rest of my career in my current organization," "My organization has a great deal of personal meaning to me," "I do not feel emotionally attached to my organization," and "I do not feel a strong sense of belonging to my organization." Two of the items in this subscale were reverse-coded to reflect affective commitment. The scale demonstrated high internal consistency $(\alpha=$ $.75)$.

Normative commitment is one's perceived obligation of remaining in the organization. (Meyer \& Allen, 1991). The items in the normative commitment subscale were "Even if it were to my advantage, it would not be right to leave my organization," "My organization deserves my loyalty," "I would feel guilty if I left my organization now," and "I would not leave my organization right now due to my sense of obligation to it." The scale demonstrated high internal consistency $(\alpha=.78)$.

Continuance commitment refers to a felt need to remain at the organization (Meyer \& 
Allen, 1991). The items in the continuance commitment subscale were "It would be difficult for me to leave my organization right now, even if I wanted to," "One of the major reasons I continue to work for my organization is that leaving would require considerable personal sacrifice," "Right now, staying with my organization is a matter of necessity as much as desire," and "One consequence of my leaving my organization would be the lack of available job alternatives." The initial four-item scale demonstrated low internal consistency $(\alpha=.46)$. The removal of the item "One consequence of my leaving my organization would be the lack of available job alternatives" increased the scale's reliability to $\alpha=.54$. Therefore, this item was removed prior to analysis, resulting in a final continuance commitment scale that was comprised of three items.

\section{Procedure}

The survey was administered online via Qualtrics. The link and a request to participate in the 10-minute survey were sent to individuals in the researcher's personal and professional network through email, Facebook, and LinkedIn. When participants clicked the link, they were shown a consent form that informed them that their participation was voluntary and their responses would be anonymous. In order to continue the survey, participants had to provide their consent to participate by selecting the corresponding button. If participants did not consent, they were directed to the end of the survey. If the participants indicated their willingness to participate, they were asked a qualifying question that assessed if they were employed. If participants indicated that they were self-employed or unemployed, they were directed to the end of the survey. If participants indicated they were employed, they were directed to complete the rest of the 
survey. Participants then filled out demographic information, after which the survey concluded. The collected data was analyzed using SPSS (Version 24). 


\section{Results}

\section{Descriptive Statistics}

The means, standard deviations, and Pearson correlations for the measured variables are shown in Table 2. Participants reported moderately low levels of role conflict $(M=$ $2.40, S D=.95)$ and role ambiguity $(M=2.00, S D=.82)$. Analysis of the moderator, leadership style, revealed a roughly even split between participants who rated their supervisors as being task-oriented (51.6\%) and participants who rated their supervisors as bring relationship-oriented $(48.4 \%)$. Finally, participants reported moderate levels of affective commitment $(M=3.23, S D=.99)$, normative commitment $(M=3.00, S D=$ $1.04)$, and continuance commitment $(M=3.14, S D=.98)$. All three dimensions of organizational commitment were normally distributed.

Table 2

Means, Standard Deviations, and Bivariate Correlations among Variables $(N=126)$

\begin{tabular}{|c|c|c|c|c|c|c|c|c|}
\hline Variable & $\mathrm{M}$ & SD & 1 & 2 & 3 & 4 & 5 & 6 \\
\hline 1. Role Conflict & 2.40 & .95 & - & & & & & \\
\hline 2. Role Ambiguity & 2.00 & .82 & $.41 * * *$ & - & & & & \\
\hline $\begin{array}{l}\text { 3. Leadership Style } \\
\qquad \begin{array}{l}1=\text { Task-oriented } \\
2=\text { Relationship- } \\
\text { oriented }\end{array}\end{array}$ & - & - & .04 & $.32 * * *$ & - & & & \\
\hline 4. Affective Commitment & 3.23 & .99 & $-.30 * *$ & $-.59 * * *$ & -.10 & - & & \\
\hline 5. Normative Commitment & 3.00 & 1.04 & $-.29 * *$ & $-.41 * * *$ & -.02 & $.65 * * *$ & - & \\
\hline 6. Continuance Commitment & 3.14 & .98 & .06 & .02 & -.09 & .16 & .09 & 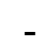 \\
\hline
\end{tabular}
Note. ${ }^{*} p<.05, * * p<.01, * * * p<.001$ 


\section{Pearson Correlations}

As shown in Table 2, there were moderate negative relationships between role conflict and the outcome variables of affective commitment $(r=-.30, p<.01)$ and normative commitment $(r=-.29, p<.01)$, such that the more respondents felt their roles were conflicting, the less emotionally and morally committed they were to the organization. Role conflict was not significantly related to continuance commitment $(r=.06, p>.05)$. Similarly, role ambiguity was moderately and negatively related to both affective commitment $(r=-.59, p<.001)$ and normative commitment $(r=-.41, p<.001)$, such that the more respondents felt their roles were ambiguous, the less emotionally and morally committed they were to the organization. Role ambiguity was not significantly related to continuance commitment $(r=.02, p>.05)$. Based on these correlations, role ambiguity was more strongly related to affective and normative commitment than was role conflict, which suggests that a lack of clear understanding of their roles better predicted employees' feelings of emotional and moral commitment than did incompatible role demands.

However, neither role conflict nor role ambiguity was related to the felt need to remain at the organization.

There was a moderate correlation between role conflict and role ambiguity $(r=.41, p$ $<.001$ ), signifying that the more contradictory one's work roles were, the more unclear role expectations were. There was no significant relationship between role conflict and the moderator variable, leadership style $(r=.04, p>.05)$. However, there was a moderate positive relationship between role ambiguity and leadership style $(r=.32, p<.001)$, such that employees who perceived their supervisors as being relationship-oriented rather than 
task-oriented reported greater levels of role ambiguity. Lastly, leadership style was not significantly related to affective commitment $(r=-.10, p>.05)$, normative commitment $(r$ $=-.02, p>.05)$, or continuance commitment $(r=-.09, p>.05)$. This result implied that supervisors' leadership style did not affect their subordinates' commitment to their organizations.

\section{Tests of Hypotheses and Research Question}

Three hierarchical multiple regression (MRC) analyses with three steps were conducted to test Hypotheses 1 and 2, and the research question. In the first step of the analysis, role conflict and role ambiguity were entered as predictors in order to assess their relationship with one's reported feelings of each type of organizational commitment. In the second step, leadership style was added to explore its incremental effect. Finally, in the third step, the interaction between role conflict and leadership style and the interaction between role ambiguity and leadership style were added in order to determine the moderating effect of leadership style on the relationships between role conflict and role ambiguity and each component of organization commitment.

Hypothesis 1 stated that leadership style would moderate the relationships between role conflict and role ambiguity and affective commitment, such that negative relationships between role conflict and role ambiguity and affective commitment would be weaker for employees who perceive their leaders as being relationship-oriented than for employees who perceive their leaders as being task-oriented. As shown in Table 3, role conflict and role ambiguity were entered in the first step as independent variables. The first step revealed that these two variables explained $36 \%$ of the variance in affective 
commitment $\left(R^{2}=.36, R^{2} a d j=.35, F(2,123)=34.05, p<.001\right)$. Thus, the role stressors significantly contributed to employees' levels of emotional attachment to their organizations. However, only role ambiguity $(\beta=-.56, t=-7.12, p<.001)$ had a significant unique contribution as a predictor. This implied that a lack of clarity about expected work behaviors was uniquely related to a desire to stay due to affection toward one's organization.

Table 3

Hierarchical MRC for the Moderating Effect of Leadership Style (Affective Commitment)

\begin{tabular}{rllll} 
& & \multicolumn{3}{c}{ Affective Commitment } \\
\hline Step 1: & Rode stressors & $R^{2}$ & $\Delta R^{2}$ & $\beta$ \\
& $\begin{array}{l}\text { Role Conflict } \\
\text { Role Ambiguity }\end{array}$ & $.36^{* * *}$ & $.36^{* * *}$ & \\
Step 2: & Leadership style & & -.07 \\
& Leadership Style & & & $-.56^{* * *}$ \\
Step 2: & Role stressors x Leadership style & $.37^{* * *}$ & .01 & \\
& $\begin{array}{l}\text { Role Conflict x Leadership Style } \\
\text { Role Ambiguity x Leadership Style }\end{array}$ & & & .10 \\
Note. $^{*} p<.05, * * p<.01, * * * p<.001$ & & & -.36 \\
\end{tabular}

In the second step, leadership style was entered. Based on the second step, leadership style alone did not account for a significant amount of variance above and beyond role conflict and role ambiguity $\left(\Delta R^{2}=.01, F(1,122)=1.55, p>.05\right)$. Therefore, leadership style did not have a significant incremental effect on affective commitment.

In the third step, the interactions between role conflict and leadership style, and role 
ambiguity and leadership style were added. The combination of the two interaction terms did not account for a significant amount of variance above and beyond the direct effects of role conflict, role ambiguity, and leadership style $\left(\Delta R^{2}=.01, F(2,120)=.72, p>.05\right)$. Therefore, the relationships between role conflict and role ambiguity and affective commitment were not moderated by leadership style, indicating that the perceived leadership style of one's supervisor did not significantly affect the negative relationships between the role stressors and employees' emotional desires to stay within the organization. Thus, Hypothesis 1 was not supported.

Hypothesis 2 stated that leadership style would moderate relationships between role conflict and role ambiguity and normative commitment, such that the negative relationships between role conflict and role ambiguity and normative commitment would be weaker for employees who perceive their leaders as being relationship-oriented than for those who perceive their leaders as being task-oriented. As shown in Table 4, role conflict and role ambiguity were entered in the first step as independent variables. The first step revealed that these two variables explained $19 \%$ of the variance in normative commitment $\left(R^{2}=.19, R^{2} a d j=.17, F(2,123)=14.08, p<.001\right)$. Thus, the role stressors significantly contributed to the degree to which employees felt morally obliged to remain at the organization. However, only role ambiguity $(\beta=-.35, t=-3.91, p<.001)$ had a significant unique contribution as a predictor. This implied that a lack of clarity about expected work behaviors was uniquely related to employees' obligations to continue working at their organizations. 
Table 4

Hierarchical MRC for the Moderating Effect of Leadership Style (Normative Commitment)

\begin{tabular}{|c|c|c|c|c|}
\hline & & \multicolumn{3}{|c|}{ Normative Commitment } \\
\hline & Predictor & $R^{2}$ & $\Delta R^{2}$ & $\beta$ \\
\hline \multirow[t]{3}{*}{ Step 1: } & Role Stressors & $.19 * * *$ & $.19 * * *$ & \\
\hline & Role Conflict & & & -.15 \\
\hline & Role Ambiguity & & & $-.35 * * *$ \\
\hline \multirow[t]{2}{*}{ Step 2: } & Leadership Style & & & \\
\hline & Leadership Style & $.20 * * *$ & .01 & .10 \\
\hline \multirow[t]{3}{*}{ Step 2: } & Role Stressors x Leadership Style & $.22 * * *$ & .03 & \\
\hline & Role Conflict x Leadership Style & & & .69 \\
\hline & Role Ambiguity x Leadership Style & & & -.57 \\
\hline
\end{tabular}

In the second step, leadership style was entered. Based on the second step, leadership style alone did not account for a significant amount of variance above and beyond role conflict and role ambiguity $\left(\Delta R^{2}=.01, F(1,122)=1.45, p>.05\right)$. Therefore, leadership style did not have a significant incremental effect on normative commitment.

In the third step, the interactions between role conflict and leadership style, and role ambiguity and leadership style were added. The combination of the two interaction terms did not account for a significant amount of variance above and beyond the direct effects of role conflict, role ambiguity, and leadership style $\left(\Delta R^{2}=.03, F(2,120)=1.90, p>.05\right)$. Therefore, the relationships between role conflict and role ambiguity and normative commitment were not moderated by leadership style, indicating that the perceived leadership style of one's supervisor did not significantly influence the negative 
relationships between the two role stressors and employees' sense of obligation to stay at their organizations. Thus, Hypothesis 2 was not supported.

Lastly, the present study posed a research question aimed at understanding the direct relationships between role conflict and role ambiguity and continuance commitment, as well as whether or not leadership style moderated the two relationships. The results of a linear regression analysis with role conflict as the predictor and continuance commitment as the outcome indicated that there was a nonsignificant association between the two $\left(R^{2}=\right.$ $.06, F(1,124)=.38, p>.05)$. When role ambiguity was entered as the predictor, it was revealed that role ambiguity was also not significantly related to continuance commitment $\left(R^{2}=.00, F(1,124)=.05, p>.05\right)$.

A final MRC analysis was ran to determine if leadership style moderated the relationships between role conflict and role ambiguity and continuance commitment. As shown in Table 5, role conflict and role ambiguity were entered in the first step as independent variables. The first step revealed that these two variables were not related to continuance commitment $\left(R^{2}=.00, R^{2} a d j=-.01, F(2,123)=.19, p>.05\right)$. Thus, role stressors did not significantly contribute to the degree to which employees felt a need to remain at the organization. 
Table 5

Hierarchical MRC for the Moderating Effect of Leadership Style (Continuance Commitment)

\begin{tabular}{|c|c|c|c|c|}
\hline & & \multicolumn{3}{|c|}{ Continuance Commitment } \\
\hline & Predictor & $R^{2}$ & $\Delta R^{2}$ & $\beta$ \\
\hline \multirow[t]{3}{*}{ Step 1: } & Role stressors & .00 & .00 & \\
\hline & Role Conflict & & & 06 \\
\hline & Role Ambiguity & & & -.00 \\
\hline \multirow[t]{2}{*}{ Step 2: } & Leadership style & & & \\
\hline & Leadership Style & .01 & .01 & -.11 \\
\hline \multirow[t]{3}{*}{ Step 2: } & Role stressors x Leadership style & .02 & .00 & \\
\hline & Role Conflict x Leadership Style & & & .21 \\
\hline & Role Ambiguity x Leadership Style & & & .10 \\
\hline
\end{tabular}

In the second step, leadership style was entered. Based on the second step, leadership style did not account for a significant amount of variance above and beyond role conflict and role ambiguity $\left(\Delta R^{2}=.01, F(1,122)=1.22, p>.05\right)$. Therefore, leadership style did not have a significant incremental effect on continuance commitment.

In the third step, the interactions between role conflict and leadership style, and role ambiguity and leadership style were added. The combination of the two interaction terms did not account for a significant amount of variance above and beyond the direct effects of role conflict, role ambiguity, and leadership style $\left(\Delta R^{2}=.00, F(2,120)=.23, p>.05\right)$. Therefore, the relationships between role conflict and role ambiguity and continuance commitment were not moderated by leadership style, indicating that the perceived leadership style of one's supervisor did not significantly impact associations between the 
two role stressors and employees' beliefs that they had to stay at their organizations to avoid the costs of leaving. 


\section{Discussion}

The purpose of this study was to further examine relationships between role conflict and role ambiguity and three types of organizational commitment. Although numerous studies have explored direct relationships between these variables in the workplace, none have yet studied the moderating effect of leadership style, as measured by task and relationship orientations.

\section{Summary of Findings}

Hypothesis 1 predicted that there would be a weaker negative relationship between conflict and ambiguity tied to employees' roles and their emotional attachment to the organization for those who believed their supervisors focused on fostering meaningful relationships over maintaining performance. Contrary to this expectation, leadership style did not moderate the relationships between role conflict and role ambiguity and affective commitment. Hypothesis 2 predicted the same moderating effect of leadership style for the negative relationships between role conflict and role ambiguity and normative commitment. Again, this hypothesis was not supported, which suggests that leadership style did not influence the negative relationships between the role stressors and employees' beliefs that they ought to remain at the organization.

In regard to this study's research question, results showed that both role conflict and role ambiguity were unrelated to continuance commitment. Furthermore, leadership style did not serve as a moderator of these relationships. While existing research examining these relationships had resulted in mixed findings, the current study shines light on the 
notion that role stress does not lend itself to a significant change in continuance commitment.

The lack of significant results can be attributed to several reasons. One possible explanation for this may be the varying levels of interaction between an employee and his or her supervisor. Some employees may see their team members and their role as being interconnected, while others may see them as separate aspects of their jobs. In the latter case, regardless of their leadership style, the exchanges occurring between supervisors and their direct reports may not be frequent enough to result in decreased commitment to the organization due to increasing levels of role stress. Even within jobs that are teamoriented, it is possible that a leader's behavioral tendencies result in additional role-related stress for his or her team members. Task-oriented leadership may place an additional amount of pressure on employees who are already stressed, whereas relationship-oriented leadership may be distracting for others, causing them to lose focus from their responsibilities and become stressed due to fast-approaching deadlines. In these ways, either of the two leadership styles can be a cause of additional stress, preventing one style from being more beneficial in reducing the negative impact of role-related stress.

Another possible explanation for the results obtained is that employees might have different perceptions of these two leadership styles based on what they value more. It is possible that type of job or industry plays a role in determining what employees prioritize in their careers. For example, some employees might see their supervisors' efforts to ensure that their well-being is high as a positive gesture. However, other employees may appreciate the professional development that comes with a strict adherence to 
accomplishing short-term tasks and long-term goals. Thus, it is possible that the congruence between a supervisor's leadership style and his or her subordinate's preferred leadership style interacts with role stressors to influence organizational commitment.

The findings of the research question could be due to the "need" aspect of remaining committed. In cases where an employee's need to stay is caused by external factors such as economic costs, continuance commitment would not necessarily decrease or increase as one deals with greater levels of internal role-related stress. Regardless of the effect the style of one's leader may have on one's internal work experience, an employee's existing need to remain at the organization to avoid the costs of leaving would remain unchanged.

\section{Theoretical Implications}

This study found that leadership style did not moderate relationships between role stressors and the three types of organizational commitment. However, unlike research by Abassi (2018), which showed that different levels of leadership styles affect relationships between role stressors and employee health, this study compared one style to another. One implication of this study is that the extent to which role stressors negatively affect employee commitment does not appear to differ for employees who have task-oriented supervisors and those who have relationship-oriented supervisors. It is also possible that other leadership styles may moderate relationships between role stressors and organizational commitment, or that leadership style moderates the relationships found when studying another predictor variable, outcome variable, or both. Therefore, there is a need for further research using the variables measured in this study.

The direct relationships found in this study were consistent with previous research 
showing that negative relationships exist between role stressors and both affective and normative commitment (Agarwal \& Ramaswami, 1993; King \& Sethi, 1997; Lopopolo, 2002; Malik \& Malik, 2010; Yousef, 2002; Zakari, 2011). Role ambiguity's negative effect on both types of commitment was greater than that of role conflict, adding support to the literature that the two stressors should be studied separately. The nonsignificant direct relationships between role stressors and continuance commitment found in this study also align with the mixed results obtained by researchers (King \& Sethi, 1997; Yousef, 2002; Zakari, 2011). This suggests that continuance commitment should be studied in conjunction with factors that would seemingly affect employees' perceived needs to stay at an organization, such as workplace policies and benefits.

\section{Practical Implications}

Results of this study revealed that neither task- or relationship-oriented leadership is more effective in ameliorating the impact of role stressors on organizational commitment, which implies that leaders should not alter the extent to which they display either to address role-related stress. Instead, leaders should continue to display both types of behaviors in order to fulfill subordinates' task- and relationship-related needs and help instill the balance that is needed to sustain positive team dynamics.

Despite the nonsignificant results obtained in this study, it is necessary for leaders to be aware of the impact their actions have on their subordinates. Although neither of the two leadership styles studied was more impactful in reducing the negative consequences of role stress, there may be other leadership characteristics that influence the relationships between role stress and organizational commitment. Leaders should remain cognizant of 
the potential benefits of showing additional behaviors beyond these two leadership styles, for example, guiding employees to manage their stress through specific actions. For organizations that seek to maintain organizational commitment among employees, leaders should take a more proactive leadership stance by directing their efforts toward equipping employees with the tools and resources they need to successfully manage role stressors that are inevitable due the fast-changing nature of work.

\section{Strengths of the Study}

A strength of the study is that it examined the moderating effect of leadership style on the relationships between role stressors and each type of organizational commitment separately, which has never been studied. This study adds value to existing literature by showing that leadership style does not have a strong influence on the role stressorganizational commitment relationships, suggesting that leaders should focus on other workplace factors when their employees face role stress.

Another strength of this study is that it compared one leadership style to another. As almost all leadership behaviors can be categorized as either task or relationship-oriented, the results of this study can be applied to virtually all organizational leaders, who demonstrate behaviors that fall into one style or the other, if not both.

\section{Limitations of the Study and Directions for Future Research}

The present study has several limitations that should be addressed. One limitation of this study is that it involved studying a moderator that is potentially subjective in the way it is judged; it is plausible that certain employees perceive task and relationship orientation differently. For example, the nature of one's job or one's own behavioral inclinations can 
greatly impact the way an employee feels about task- and relationship-oriented behaviors. It may be worthwhile for future studies to control for organizational variables such as job type, job level, and industry, as well as individual-level variables such as preferred leadership style or resilience, which can potentially interact with role stressors to influence employee commitment.

A second limitation of this study is that two leadership styles that leaders tend to display simultaneously were compared to each other. Although most leaders can be associated more with one style over the other, the lack of a strong difference between the amount of task- and relationship-oriented behaviors displayed by supervisors may be why leadership style did not significantly influence the impact of role stressors on organizational commitment. Future studies that involve leadership behaviors that are dependent and lie on opposite ends of a single leadership continuum may be more successful in finding a significant moderation effect.

As the respondents in this study were primarily part of my personal network, their relatively young age is an additional limitation within this study. Given that certain aspects of organizational commitment form over time, a lack of substantial work experiences may have caused younger respondents to report lower levels of commitment than older respondents. Future studies should seek to include a more balanced mix of age groups.

Lastly, the cross-sectional design of this study was a limitation. Measures of organizational commitment obtained at a single point in time may be less resistant to extraneous factors such as newly implemented workplace changes, which can 
momentarily impact employees' psychological states. Future studies that utilize a longitudinal design would thus obtain a more accurate picture of the processes by which role stressors lead to negative consequences and how leaders help to mitigate such consequences.

\section{Conclusion}

The goal of this study was to explore leadership style as a moderator of the relationships between role stressors and organizational commitment. Although leadership style, as conceptualized in this study, did not serve as a moderator, there is a need for continued research on this topic. Given the negative association between role stressors and organizational commitment, and the serious consequences of low commitment, it is vital for organizations to have a deeper understanding of the aspects of one's job that influence the role stress-organizational commitment relationships. 


\section{References}

Abbasi, S. G. (2018). Leadership styles: Moderating impact on job stress and health. Journal of Human Resources Management Research, 2018, 1-11.

Ackfeldt, A. L., \& Malhotra, N. (2013). Revisiting the role stress-commitment relationship: Can managerial interventions help? European Journal of Marketing, 47, 353-374.

Agarwal, S., \& Ramaswami, S. N. (1993). Affective organizational commitment of salespeople: an expanded model. Journal of Personal Selling \& Sales Management, 8, 49-70.

Bass, B. M. (1985). Leadership and performance beyond expectations. New York, NY: Free Press.

Beck, K., \& Wilson, C. (2000). Development of affective organizational commitment: A cross-sequential examination of change with tenure. Journal of Vocational Behaviour, $56,114-136$.

Conger, J. A., \& Kanungo, R. N. (1987). Toward a behavioral theory of charismatic leadership in organizational settings. Academy of Management Review, 12, 637-647.

Cooper, C. L., \& Marshall, J. (1976). Occupational sources of stress: A review of the literature relating to coronary heart disease and mental ill health. Journal of Occupational Psychology, 4, 11-28.

Cropanzano, R., \& Mitchell, M.S. (2005). Social exchange theory: An interdisciplinary review. Journal of Management, 31, 874-900.

Daft, R. L. (2008). The leadership experience (4th ed.). Mason, OH: Thomson South Western.

Forsyth, D. R. (2010). Group Dynamics (5th ed.). Belmont, CA: Wadsworth Cengage Learning.

Greenleaf, R. K. (1977). Servant leadership: A journey into the nature of legitimate power and greatness. Mahwah, NJ: Paulist Press.

Hart, P. (1994). Teacher quality of work life: Integrating work experiences, psychological distress and morale. Journal of Occupational and Organizational Psychology, 67, 109-132 
Hartline, M. D., \& Ferrell, O. C. (1996). The management of customer-contact service employees: An empirical investigation. Journal of Marketing, 60, 52-70.

Hersey, P., \& Blanchard, K. H. (1969). Life cycle theory of leadership. Training \& Development Journal, 23, 26-34.

Jackson, T. A., Meyer, J. P., \& Wang, X. (2013). Leadership, commitment, and culture: A meta-analysis. Journal of Leadership \& Organizational Studies, 20, 84-106.

Kahn, R. L., \& Byosiere, P. (1992). Stress in organizations. In M. D. Dunnette \& L. M. Hough (Eds.), Handbook of industrial and organizational psychology (pp.571-650). Palo Alto, CA, US: Consulting Psychologists Press.

Kahn, R. L., Wolfe, D. M., Quinn, R. P., Snoek, J. D., \& Rosenthal, R. A. (1964). Organizational stress: Studies in role conflict and ambiguity. New York: John Wiley \& Sons.

King, R. C., \& Sethi, V. (1997). The moderating effect of organizational commitment on burnout in information systems professionals. European Journal of Information Systems, 6, 86-96.

Lewin, K., Lippitt, R., \& White, R. K. (1939). Patterns of aggressive behavior in experimentally created social climates. Journal of Social Psychology, 10, 271-301

Lopopolo, R. B. (2002). The relationship of role-related variables to job satisfaction and commitment to the organization in a restructured hospital environment. Physical Therapy, 82, 984-999.

Luchak, A. A., \& Gellatly, I. R. (2007). A comparison of linear and nonlinear relations between organizational commitment and work outcomes. Journal of Applied Psychology, 92, 786-793.

Malik, O. F., Waheed, A., \& Malik, K. U. R. (2010). The mediating effects of job satisfaction on role stressors and affective commitment. International Journal of Business and Management, 5, 223-235.

Mathieu, J. E., \& Zajac, D. M. (1990). A review and meta-analysis of the antecedents, correlates, and consequences of organizational commitment. Psychological Bulletin, 108, 171-194.

Meyer, J. P., \& Allen, N. J. (1991). A three component conceptualization of organizational commitment. Human Resource Management Review, 1, 61-98. 
Meyer, J. P., Allen, N. J., \& Smith, C. A. (1993). Commitment to organizations and occupations: extension and a test of a three-component conceptualization. Journal of Applied Psychology, 78, 538-551.

Netemeyer, R. G., Maxham, J. G. III, \& Pullig, C. (2005). Conflicts in the work-family Interface: links to job stress, customer service employee performance, and customer purchase intent. Journal of Marketing, 69, 130-143.

Newstrom, J. W., \& Davis, K. (1993). Organizational behavior: Human behavioral work. (9th ed.). New York: McGraw-Hill, Inc.

O'Reilly, C., \& Chatman, J. (1986). Organizational commitment and psychological attachment: The effects of compliance, identification, and internalization on prosocial behavior. Journal of Applied Psychology, 71, 492-499.

Örtqvist, D., \& Wincent, J. (2006). Prominent consequences of role stress: A metaanalytical review. International Journal of Stress Management, 13, 399-422.

Rizzo, J., House, R., \& Lirtzman, S. (1970). Role conflict and ambiguity in complex organization. Administrative Science Quarterly, 15, 150-163.

Salancik, G. R. (1977). Commitment and the control of organizational behavior and belief. In B. M. Straw and G. R. Salancik (Eds.), New Directions in Organizational Behavior (pp. 1-54). Chicago, IL: St. Claire Press.

Stogdill, R. M. (1948). Personal factors associated with leadership: A survey of the literature. The Journal of Psychology, 25, 35-71.

Stogdill, R. M. (1974). Handbook of leadership: A survey of the literature. New York, NY: Free Press.

Yousef, D. (2002). Job satisfaction as a mediator of the relationship between role stressors and organizational commitment. Journal of Managerial Psychology, 17, 250-266.

Zakari, N. (2011). The impact of nurse role ambiguity and role conflict on nursing faculty commitment in Saudi Arabia. Life Science Journal-Acta Zhengzhou University Overseas Edition, 8, 179-186. 


\section{Appendix}

Survey Items

\section{Role Conflict}

1. I have to oppose rules or policies in order to carry out my work assignments.

2. I do things in my work that are accepted by one person but not accepted by others.

3. I receive conflicting work requests from two or more people.

\section{Role Ambiguity}

1. My job has clearly defined goals and objectives. *

2. I feel certain about how much authority I have in my job. *

3. I know what the responsibilities are in my job role. *

\section{Affective Commitment}

1. I would be happy to spend the rest of my career in my current organization.

2. My organization has a great deal of personal meaning to me.

3. I do not feel emotionally attached to my organization. *

4. I do not feel a strong sense of belonging to my organization. *

\section{Normative Commitment}

1. Even if it were to my advantage, it would not be right to leave my organization.

2. My organization deserves my loyalty.

3. I would feel guilty if I left my organization now.

4. I would not leave my organization right now due to my sense of obligation to it.

\section{Continuance Commitment}

1. It would be difficult for me to leave my organization right now, even if I wanted to.

2. One of the reasons I continue to work for my organization is that leaving would involve considerable personal sacrifice.

3. Right now, staying with my organization is a matter of necessity as much as desire.

4. One consequence of my leaving my organization would be the lack of available job alternatives. 


\section{Task-Oriented Leadership}

1. My supervisor sets standards of performance for group members.

2. My supervisor defines role responsibilities for each group member.

3. My supervisor makes suggestions about how to solve problems.

4. My supervisor encourages group members to do high-quality work.

5. My supervisor develops action plans for how the work is to be done.

6. My supervisor provides criteria for what is expected of the group.

\section{Relationship-Oriented Leadership}

1. My supervisor communicates with group members about their personal concerns.

2. My supervisor is friendly with members of the group.

3. My supervisor helps group members get along with each other.

4. My supervisor shows concern for the well-being of group members.

5. My supervisor helps group members feel comfortable.

6. My supervisor discloses his or her thoughts and feelings to group members.

* Indicates that survey items were reverse-coded. 